\title{
Respiratory complications of amyotrophic lateral sclerosis
}

\author{
Monserrat E. Arroyo-Rojas, Martha G. Torres-Fraga, Yadira G. Rodríguez-Reyes, Selene Guerrero-Zúniga, \\ and José L. Carrillo-Alduenda* \\ Sleep Medicine Unit, Instituto Nacional de Enfermedades Respiratorias Ismael Cosío Villegas, Mexico City, Mexico
}

\begin{abstract}
Amyotrophic lateral sclerosis (ALS) is a progressive and fatal neurodegenerative disease that inevitably affects the respiratory system, and part of its treatment focuses on improving symptoms and minimizing its respiratory complications which arể the main cause of death; thus, the purpose of the following review is to describe the pulmonary involvement of ALS, to propose diagnostic/monitoring guidelines, and to expose its therapeutic options. The alveolar hypoventilation syndrome and the ppoor management of bronchial secretion are the main respiratory difficulties secondary to ALS and they are due to the weakiess of the muscles that generate respiration; in this way, the periodic assessment of respiratory function is imperative for monitoring and detecting these complications in early stages. The care of patients with ALS should be multidisciplinary=and ideally should be performed in specialized centers; non-invasive mechanical ventilation and assisted cough (manual or mechanical) are the two most cost/effective techniques to treat alveolar hypoventilation and poor secretion management to increase survival, improve symptoms, and increase quality of life.
\end{abstract}

Key words: Amyotrophic lateral sclerosis. Hypoventilation. Respiration. Artificial. Respiratory function tests.

\section{Complicaciones respiratorias de la esclerosis lateral amiotrófica}

\section{Resumen}

La esclerosis lateral amiotrófica (ELA) es una enfermedad neurodegenerativa progresiva y mortal que inevitablemente afecta el sistema respiratorio, por lo que parte de su tratamiento se enfoca en mejorar los síntomas y minimizar sus complicaciōnes respiratorias, que son la principal causa de muerte; así, el objetivo de la siguiente revisión es describir la afectación pulmônar de la ELA, proponer pautas de diagnóstico/monitoreo y exponer sus opciones terapéuticas. El síndrome de hipoventilación alveolar y el mal manejo de secreción bronquial son las principales alteraciones respiratorias secundarias a la ELA $\bar{y}$ se deben a la debilidad de los músculos que generan respiración. De esta manera, la evaluación periódica de la función resspiratoria es imprescindible para controlar y detectar estas complicaciones en las etapas iniciales. La atención de los pacièntes con ELA debe ser multidisciplinaria e idealmente debe realizarse en centros especializados. La ventilación mecánica hô invasiva y la tos asistida (manual o mecánica) son las dos técnicas más rentables para tratar la hipoventilación alveolarây el manejo deficiente de las secreciones para prolongar la supervivencia, mejorar los sintomas y aumentar la calidad de vida.

Palabras clave: Esclerosis lateral amiotrófica. Hipoventilación alveolar. Respiración artificial. Pruebas de función respiratoria.

\section{Correspondence:}

*José Luis Carrillo-Alduenda

Sleep Medicine Unit

National Institute of Respiratory Diseases

Ismael Cosio Villegas, Mexico

Date of reception: 18-04-2019

Date of acceptance: $27-06-2019$

E-mail: jlcarrillo14@ hotmail.com

DOI: 10.24875/RMN.19000074
Available online: $04-12-2019$ Rev Mex Neuroci. 2019;20(6):27 $\underline{\underline{5}-283}$ www.revmexneurociencia.com 1665-5044/@ 2019 Academia Mexicana de Neurología A.C. Published by Permanyer. This is an open access article under the CC BY-NC-ND license (bttp:// creativecommons.org/licenses/by-nc-nd/4.0/). 


\section{Introduction}

Amyotrophic lateral sclerosis (ALS) is a progressive and fatal neurodegenerative disease that has a worldwide incidence of 0.6-3.3 cases per 100,000 inhabitants. It is characterized by the death of the upper motor neurons located in the motor cortex and lower motor neurons (LMN) located in the brainstem and spinal cord ${ }^{1-5}$. The degeneration of the corticospinal axons causes thinning and scarring (sclerosis) of the lateral columns of the spinal cord and as the brainstem and spinal motor neurons die a thinning of the ventral roots and a denervational atrophy (amyotrophy) of the muscles of the tongue, oropharynx and extremities occurs, originating muscular rigidity, and spasticity; when LMN are affected, initially, they show excessive electrical irritability, producing spontaneous muscle spasms (fasciculations) but as they degenerate, they lose synaptic connectivity with their muscles causing the consequent atrophy ${ }^{5}$.

Symptoms usually begin insidiously with the involvement of a specific group of muscles, and then they progressively generalize, it should be noted that the function of the neurons of the oculomotor nuclei and Onuf's nucleus is usually preserved until the end of the disease ${ }^{1-5}$, in approximately one-third of the cases the manifestations begin in the bulbar muscles and $<3 \%$ of the cases start directly with respiratory muscle weakness (presenting as an unexplained hypercapnic respiratory failure $)^{1,2,6}$.

In Mexico, there are few data about this condition, a retrospective longitudinal study estimated a presence between 5000 and 7000 cases and described Mexican patients as usually male (male:female ratio of 1.8:1), mean age of onset $47.5 \pm 10.5$ years, with spinal involvement in $66 \%$ of the cases and bulbar affection in $34 \%$, the overall average survival from the onset of symptoms was 68.6 months and 57.8 months since the diagnosis; $3.3 \%$ of the cases were classified as family related ${ }^{3,7}$.

The evolution of ALS to respiratory failure is inevitable and its treatment is mainly aimed to improve symptoms and minimizing the two main pulmonary complications: (1) alveolar hypoventilation (hypercapnic respiratory failure) and (2) poor management of bronchial secretions ${ }^{1}$; the objectives of the following review are to describe these complications, to propose diagnostic/monitoring guidelines, and to expose the therapeutic options available for the respiratory complications of ALS.

\section{Effects of ALS on respiratory muscles}

The physiological consequences of ALS on the respiratory system are directly secondary to the weakness of the respiratory muscles, which can be divided as follows:

- Muscles of inspiration: the muscles involved in inspiration are the diaphragm, sternocleidomastoid, scalenes, and external intercostals ${ }^{4}$, they generate the ventilation and its weakness, especially that of the diaphragm, leads to a decrease in tidal volume (amount of air entering the lung in each breath with normal effort) ${ }^{8}$; as the muscle weakness progresses, patients develop a restrictive respiratory pattern - with progressive reduction of pulmonary ventilation until it ends in alveolar hypoventilation and subsequent hypercapnic respiratory failure 4,9 ; these alterations manifest as dyspnea, fatigue, orthopnea, night/morning headache, nighttime choking, use of accesšory muscles of breathing, and paradoxical breathing when adopting the supine position ${ }^{9-12}$.

- Muscles of expiration: the main expiratory muscles are the rectus abdominis, internal and externalcabdominal obliques, the transverse abdominal and the internal intercostal muscles; the decrease in the strength of these muscles generates an ineffective cough with the consequent retention of pulmonary secretions and recurrent infections $s^{4,8}$.

- Bulbar muscles: bulbar muscular weakness, which involves the facial, oropharyngeal, and laryngeal muscles; may affect the ability to speak, swallow, protect the lower airway, and eliminate bronchiabsecretions; its alteration leads to an ineffective cough, poor handling of secretions, increases the risk of aspiration and makes less tolerable the use of a non-invasive mechanical ventilation device (NIMV), vide infra; the most important symptoms secondary to this alteration are: laryngospasm, sialorrhea, dysphagia, and dysarthria ${ }^{8}$.

\section{Evaluation of the pulmonary function i patients with ALS}

Periodic assessment of respiratory function is imperative to detect early respiratory complications of ALS these evaluations should be performed at the time of diagnosis and subsequently every 3-6 months, even in the absence of respiratory symptoms ${ }^{4}$. Respiratory function tests in patients with ALS can be classified as follows:

- Direct measurements of muscle strength are those tests that directly measure the strength of the respiratory muscles.

- Pleural pressure: it involves the placement of a catheter in the lower third of the esophagus and connect it to a pressure transducer, it is the gold 
standard for measuring diaphragmatic force; however, little is indicated because of its invasivity ${ }^{9,11}$.

- Maximum inspiratory pressure (MIP): it is a sensitive marker of diaphragmatic weakness in the early stages of ALS and correlates with survival. Normal values almost always exclude inspiratory muscle weakness and pressure lower than $-40 \mathrm{cmH}_{2} \mathrm{O}$ indicates significant inspiratory muscle weakness. When there is bulbar involvement, patients often cannot perform this procedure correctly due to the inability to form a seal around the mouthpiece (the test is done by placing a focimeter in the mouth and doing a forced inhalation) ${ }^{12}$.

- Sniff nasal inspiratory pressure (SNIP): in this test, the sensor is placed in the nose, which avoids the need to seal the mouth, it is not affected by bulbar weakness which makes it very useful in advanced stages of the disease ${ }^{4}$, SNIP correlates adequately with transdiaphragmatic pressure. A SNIP $<40 \mathrm{~cm}$ $\mathrm{H}_{2} \mathrm{O}$ correlates with nocturnal hypoxemia ${ }^{13,14}$, while a SNIP $>70 \mathrm{~cm} \mathrm{H}_{2} \mathrm{O}$ for men and $>60 \mathrm{~cm} \mathrm{H}_{2} \mathrm{O}$ for women excludes diaphragmatic weakness ${ }^{12}$.

- Maximum expiratory pressure: a value $<40 \mathrm{~cm}$ $\mathrm{H}_{2} \mathrm{O}$ suggests expiratory weakness ${ }^{4,12}$.

- Indirect measurements of respiratory muscle strength are those tests that measure lung volumes and flows, which indirectly represents an estimate of the strength of the respiratory muscles, especially the diaphragm:

- Spirometry: the most important parameter measured in spirometry for this group of patients is the vital capacity (VC), usually measured through a forced maneuver (forced VC) and more rarely through an unforced or slow expiration (slow VC). Hypercapnic respiratory failure is particularly common with a $\mathrm{VC}$ of $<15 \mathrm{ml} / \mathrm{kg}$ or an absolute value of $1 \mathrm{~L}$ or less ${ }^{12}$. Most centers consider a reduction of the VC of $<50 \%$ as an indication to initiate NIMV; however, the diaphragmatic weakness could be moderate or severe before the VC reaches this point $^{4,9}$. The $\triangle \mathrm{VC}$ (VC in the sitting position - VC in the supine position) correlates very well with the diaphragm force measured by transdiaphragmatic pressure $\left(r^{2}=0.76, p<0.001\right)^{4}$ and a $25 \%$ drop should be considered at as a sign of compromise the respiratory function ${ }^{10,12}$. The relationship between VC and muscle strength is not linear, so it is a sensitive marker only in moderate to severe stages of the disease, another limitation of this test is a possible incorrect sealing of the mouth which can alter the measurements ${ }^{12}$, despite this, repeated VC evaluations are an efficient way to detect
Table 1. Definition of hypoventilation during sleep adjusted to moderate altitudes

A) Elevation of $\mathrm{PCO}_{2}$ (or a surrogate) $>50 \mathrm{mmHg}$ for $10 \mathrm{~min}$

B) Elevation $>10 \mathrm{mmHg}$ of $\mathrm{PCO}_{2}$ (or a surrogate) during sleep compared to the value of awake and supine, up to a value $>$ $45 \mathrm{mmHg}$ for $10 \mathrm{~min}$

The patient can meet any of the two criteria.

$\mathrm{mmHg}$ : millimeters of mercury, $\mathrm{PCO}_{2}$ : carbon dioxide pressure.

respiratory muscle weakness making it a simple, accessible and reliable follow-up test ${ }^{8,13}$.

- Peak cough flow (PCF): it is done with a peak flow meter that is placed in the mouth (requires mouth sealing and is useful when there is bulbar integrity) or through a mask (do not require oral sealing and is used in the presence of bulbar impairment) and the patient is asked to cough heavily on threefoccasions, taking into account only the highest value, a value $<270 \mathrm{~L} / \mathrm{min}$ means that the cough is 育effective and indicates the need to implement asssistance techniques for cough, while $<160 \mathrm{~L} / \mathrm{min}$ predicts respiratory failure ${ }^{9,12}$.

- Gas exchange tests: arterial blood gas analysis is the only gas exchange test useful in patients with ALS and should be performed in all patients; in advañced stages of the disease it is the best indicator of the need for mechanical ventilation when there is a.confirmation of a decrease in $\mathrm{PaO}_{2}$ and the elevation of $\mathrm{PaCO}_{2}$ and $\mathrm{HCO}_{3}^{4,12,14}$.

- Sleep studies: between $17 \%$ and $76 \%$ of patients with ALS have a respiratory sleep disorder, the most frequent and feared alteration is the sleep-related hipoventilation syndrome; however, it must be considered that patients with bulbar affection have a high risk of obstructive apneas, figure 1. Sleep studies in patients with ALS can be summarized as follows:

- Polysomnography (PSG): it is the gold standard technique for diagnosing sleep disorders of breathing in patients with ALS, the suggested signals to record in this group of patients include: electroencephalogram, electro-oculogram, chin electromyography, snoring, respiratory flow-through two channels (nasal pressure cannula and oronasal thermal sensor), respiratory effort (band in chest and abdomen, ideally inductance plethysmography), electrocardiogram (DII), pulse oximetry, carbon dioxide (can be transcutaneous or exhated), tibialis anterior electromyography, and body position. Internationally, hypoventilation during sleep is 


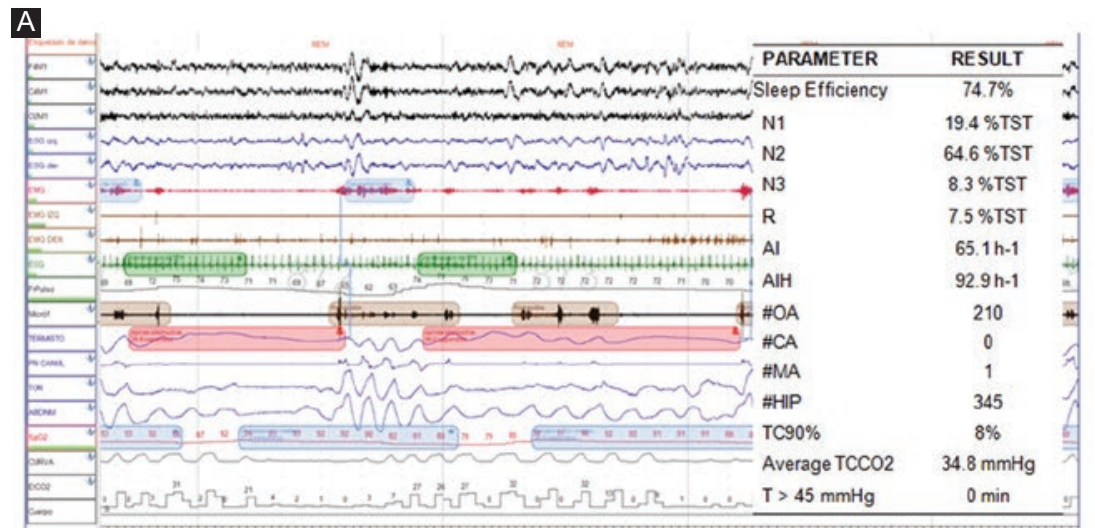

\section{B}

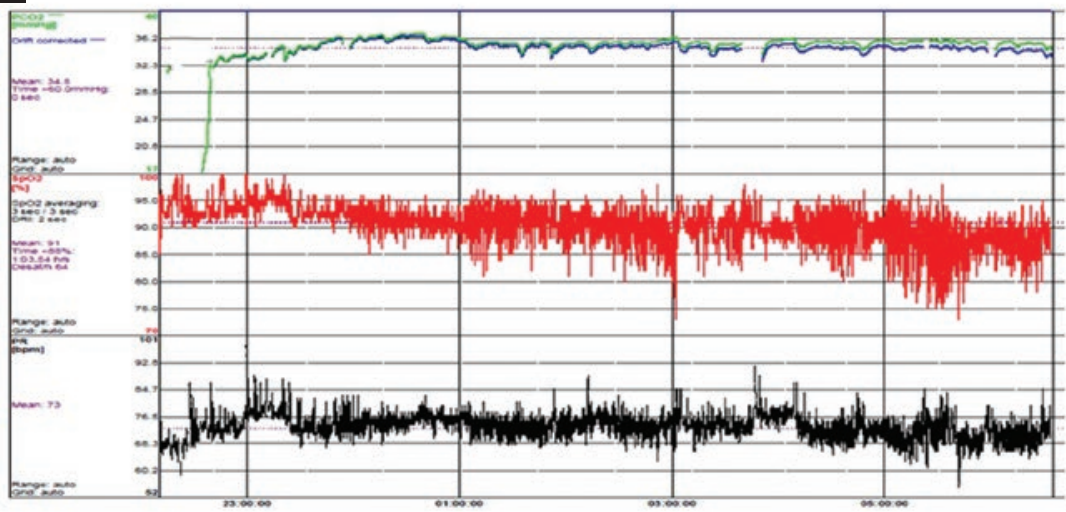

C
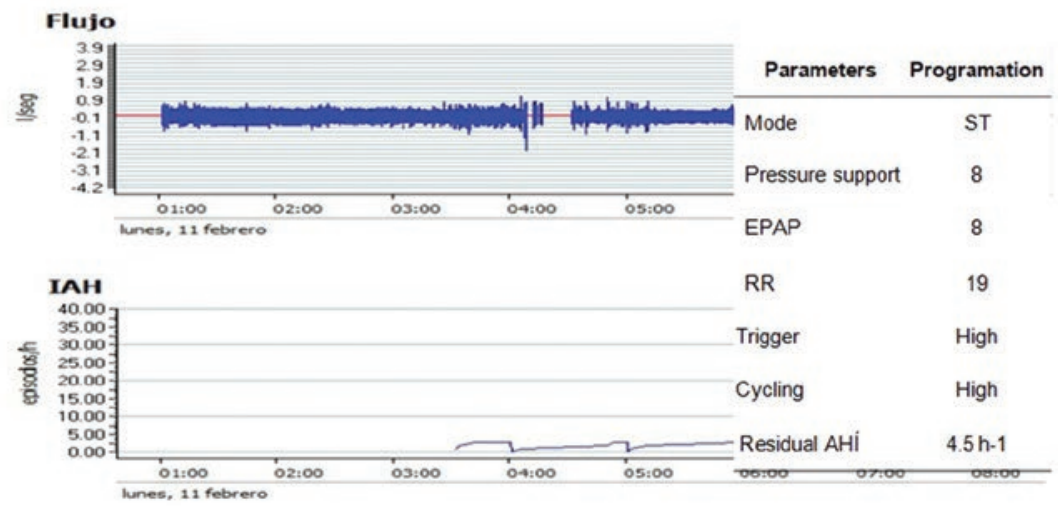

Figure 1. We present the case of a 56-year-old woman diagnosed with ALS with bulbar disease, sent to our service for habitual and intense snoring, witnessed apneas, and excessive daytime sleepiness. The patient presented 26 points on the Bulbar Affectation Scale of Norris, the gasometry in wakefulness was normal and she presented a peak cough flow measured with a mask of $290 \mathrm{~L} / \mathrm{min}$. A: Image of polysomnography compacted at 2 min with an increased superficial steep (N1 and N2), decreased R, and obstructive sleep apneas. B: Transcutaneous capnography obtained during polysomnography, the ventilation during the study was normal. C: Therapeutic test with a bilevel ST positive pressure equipment programmed in the outpatient clinic, a stable flow curve and the optimum residual hypopnea apnea index are observed.

AHI: apnea hipopnea index; AI: arousal index; CA: central apneas; HIP: hypopneas; MA: mixed apneas; mmHg: millimeters of mercury; N: no rapid eye movements sleep; OA: obstructive apneas; R: rapid eye movement sleep; RR: respiratory rate; TCCO2: transcutaneous carbon dioxide; TC $90 \%$ : < $90 \%$ saturation time expressed as $\%$ of TST; TST: total steep time; T > $45 \mathrm{mmHg}$ : time in minutes with TCCO2 $>45 \mathrm{mmHg}$.

defined when the PSG meets any of the following criteria: (a) an elevation of $\mathrm{PCO}_{2}$ (or a surrogate) $>55 \mathrm{mmHg}$ for $10 \mathrm{~min}$, or (b) an elevation >
$10 \mathrm{mmHg}$ of $\mathrm{PCO}_{2}$ (or a surrogate) during slêep, compared to the awake and supine value, up to a value $>50 \mathrm{mmHg}$ for $10 \mathrm{~min}$; this definition is 
Table 2. Essential pulmonary function tests in the follow-up of patients with ALS

\begin{tabular}{|l|l|}
\hline $\begin{array}{l}\text { ALS without bulbar } \\
\text { affectation }\end{array}$ & $\begin{array}{l}\text { ALS with bulbar } \\
\text { affectation }\end{array}$ \\
\hline $\begin{array}{l}\text { Spirometry + maximum } \\
\text { inspiratory pressure }\end{array}$ & $\begin{array}{l}\text { Sniff nasal inspiratory } \\
\text { pressure }\end{array}$ \\
\hline Gasometry & Gasometry \\
\hline $\begin{array}{l}\text { Peak cough flow with } \\
\text { mouthpiece }\end{array}$ & Peak flow of cough with mask \\
\hline
\end{tabular}

ALS: amyotrophic lateral sclerosis.

adequate when the study is carried out at sea lev$\mathrm{el}^{15,16}$, but it must be considered that this definition requires adjustment for moderate altitudes such as Mexico City, table 1. The most reported alteration in sleep architecture among patients with ALS is the decrease in the percentage of rapid eye movement $(R)$ with increased in N1 stage (non-rapid eye movement), which has been associated with decreased survival ${ }^{17,18}$. The $\mathrm{R}$ stage of sleep represents a period of vulnerability for the respiratory mechanics of patients with ALS and is usually the initial moment for the respiratory complications, since muscular atony occurs with loss of the contribution of the respiratory accessory muscles over the tidal volume and the diaphragm is the sole driver of ventilation, this weakness can cause severe alveolar hypoventilation that leads to sustained desaturation and hypercapnia 4,8,12,16,17.

- Respiratory polygraph or simplified sleep study: consists of recording only cardiorespiratory variables during sleep, the most used are: respiratory flow, effort, snoring, pulse oximetry, heart rate, and body position, eliminating sleep stages; however, they also do not allow the measurement of $\mathrm{CO}_{2}$, their role in the diagnosis of respiratory disorders of sleep in patients with ALS is limited.

- Nighttime oximetry: it is the most available sleep test, it detects desaturation events; however, it cannot provide information about ventilation and sleep architecture; it has been found abnormal nocturnal oximetry in $40 \%$ of patients with ALS without respiratory symptoms, normal respiratory function tests, and normal electrodiagnostic tests of the phrenic nerve and diaphragm ${ }^{18}$. Nocturnal desaturation correlates with inspiratory muscle weakness and can be used as a guide to initiate NIMV in the absence of PSG; it has been reported that patients who start using NIMV based on nocturnal desaturation can improve their survival ${ }^{4}$.
- Night capnography: currently, there are capnography devices with transcutaneous measurement, which also incorporate pulse oximetry, which could be üseful for diagnosing hypoventilation during sleep, figure 1; however, its diagnostic performance has not been evaluated; at this time, its best indication is as follow-up once the NIMV has been started.

The pulmonary function tests indispensable in patients with ALS are summarized in table 2.

\section{Treatment of respiratory complications of ALS}

The therapeutic options for modifying the disease are limited; currently, riluzole and edaravone are the only two drugs authorized by the U. S. Federal Drug Administration to reduce deterioration and slow down the progression of $A L S^{19}$, so, much of the therapy focuses on the management of respiratory complications.

\section{Treatment of alveolar hypoventilation}

\section{NIMV}

In patients with ALS, respiratory muscle disease with progression to alveolar hypoventilation is unavoidable and cost/benefit its best treatment is NIMV, which prolongs survival and improves symptoms and quality of life $^{20}$. The best moment to initiate NIMV is when there is hypercapnia (hypoventilation) at night with diutrnal eucapnia, so waiting for the onset of daytime hypercapnia to initiate NIMV may be a risk factor to develop acute respiratory failure, but, starting the NIMV in the absence of symptoms or nocturnal hypoventilation may not offer benefits, however, predicting this exact moment of nocturnal hypercapnia with diurnal eucapnia can be difficult, possibly the best way to diagnose it is with serial gasometries and PSGs; however, this may not be accessible, in such a way, the respiratory function tests can be very useful ${ }^{21-23}$, in the absence of PSG the indications to initiate NIMV in patients with ALS are: - Symptoms: mainly dyspnea and orthopnea ${ }^{15}$.

- VC $<50 \%$ of predicted or an accelerated decrease rate $4,10,13$.

$-\mathrm{MIP}<-60 \mathrm{cmH}_{2} \mathrm{O}^{10}$.

- SNIP $<-40 \mathrm{cmH}_{2} \mathrm{O}^{13}$.

- $\mathrm{PaCO}_{2}>45 \mathrm{mmHg}$ in wakefulness ${ }^{4,10}$.

The ventilatory support is usually started at night with the objective that NIMV assumes the work of breathing during sleep ${ }^{12}$. Inspiratory and expiratory pressuresare assessed to maintain a tidal volume of $12-15 \mathrm{ml} / \mathrm{kg}$ of 
Table 3. Programming of equipment for initial NIMV

\begin{tabular}{|l|l|l|}
\hline Parameter & $\begin{array}{l}\text { ALS without bulbar } \\
\text { affectation }\end{array}$ & $\begin{array}{l}\text { ALS with bulbar } \\
\text { affectation }\end{array}$ \\
\hline Mode & Bilevel ST & Bilevel ST \\
\hline RR (rpm) & 14 a 20 & 14 a 20 \\
\hline $\begin{array}{l}\text { EPAP o } \\
\text { PEEP }\left(\mathrm{cmH}_{2} 0\right)\end{array}$ & 4 a 6 & 6 a 8 \\
\hline PS $\left(\mathrm{cmH}_{2} 0\right)$ & 6 a 8 & 6 a 8 \\
\hline Tigger & High or very high & High or very high \\
\hline Cycling & Medium or high & Medium or high \\
\hline
\end{tabular}

ALS: amyotrophic lateral sclerosis; EPAP: expiratory positive airway pressure; PEEP: positive end expiratory pressure (synonymous with EPAP); PS: pressure support; RR: respiratory rate; ST: spontaneous/time; NIMV: non-invasive mechanical ventilation.

ideal weight and an apnea-hypopnea index $<$ at $5 / h$; this goal becomes increasingly difficult to achieve with the advance of weakness, as the disease progresses, patients will generally begin to extend the use of NIMV during the day and will often progress to a continued use (homecare) ${ }^{4}$. Factors that adversely affect the tolerability of NIMV are the presence of bulbar symptoms with increased oropharyngeal secretions, cognitive disorders, and claustrophobia ${ }^{13}$.

A NIMV equipment in patients with ALS can be initiated through two methods:

- With a manual titration through a ventilatory PSG, this implies that trained personnel place a NIMV device and make a manual adjustment of the pressures and respiratory rate, directly evaluating the patient's respiratory flow and gas exchange, describing the manual titration algorithm of a ventilatory PSG is beyond the scope of this manuscript, If the reader is interested, you can consult the NIMV Mexican Clinical Practice Guideline on Sleep Disorders of Breathing of the National Center for Technological Excellence in Health at the following electronic address: www.cenetec.salud.gob.mx/descargas/gpc/CatalogoMaestro/ SS-728-14-Ventilacion_mecanica/GER_VMNI.pdf.

- Or, through an ambulatory clinical ventilation in the office, in this case, the NIMV equipment is programmed with initial parameters already standardized and their effect in the medium and long term is evaluated; in experienced personnel, this method is as good as a manual titration performed with PSG ${ }^{24}$, the initial clinical settings of a ventilator for patients with ALS are described in table 3, these parameters will depend on the presence of bulbar disease, thus, those with bulbar involvement will require greater expiratory pressure to eliminate obstructive apneas.
At the end, patients will need continuous ventilatory assistance (homecare). Once the progressive bulbar weakness prevents the ability of patients to eliminate their secretions (even with mechanical assistance), NIMV is no longer a viable treatment option, so the decision should be made to proceed with the tracheostomy or concentrate in palliation ${ }^{4}$.

\section{IMV and care at the end of life}

IMV through a tracheotomy is an option in specific circumstances:

- When NIMV is not able to maintain adequate ventilation due to the progression of the disease.

- If the use of NIMV is required during most of the day and night (> $16 \mathrm{~h} /$ day).

- Bulbar muscular deterioration that does not allow a tolerance of NIMV, with a deficient control and elimination of secretions that are not improved by pharmacological strategies and mechanically assisted coughing techniques.

- When the patient wants to maximize their survival:8, 10. IMV is strongly associated with prolonged survivat in ALS; however, an improvement in quality of life is Tess clear, patients with tracheotomy continue to experience progression of the disease, so some patients eventually progress to a state without communication or movement $t^{4}$. It is important that patients and family members recognize that the care required by patients with IMV at höme is complex, at least two highly trained and motivated family members are needed for special care of the stoma, hygiene of the cannula, and correct aspiration technique of secretions; therefore, the IMV in these patients causes an increase in the cost of treatment, with significant emotional and social impact on both the patient and their caregivers, and can reduce the quality of life of both 5.

Given that the ALS has a predictable course, it is important to discuss with the patients and caregivers the possible invasive and non-invasive management options as soon as possible, with the aim of avoiding these decisions in the context of an abrupt clinical deterioration and giving them, patients and relatives, the time to reflect; the decision to perform a tracheotomy should only be taken with the informed consent of the patient and after a careful discussion about its pros and cons $s^{4.8,23}$.

\section{Diaphragmatic pacemaker}

The use of diaphragmatic pacemakers has been investigated as a way to reduce the decline in lung function; however, randomized studies reported an increase 
in mortality, which is why they do not represent a treatment option for respiratory failure in patients with $\mathrm{ALS}^{4,13,23}$.

\section{Management of bronchial secretions in patients with ALS}

An essential mechanism of protection of the airway is the ability to cough when the clearance of bronchial secretions is impaired; this represents a serious threat to life ${ }^{25}$. Effective cough initially requires full inspiration, followed by a glottal closure and by last an intense contraction of the expiratory muscles to generate adequate pressures and flows to move the bronchial secretions ${ }^{8}$, these phases can be affected in different ways and in different magnitudes in all the neuromuscular diseases; however, in ALS the affliction at three phases are progressive and severe; thus, the diaphragmatic weakness will decrease the initial inspiration (this is the condition that takes longer to appear), the bulbar alteration will deteriorate the glottic closure and the weakness of the rectus abdominis, obliques, and internal intercostals will wear out the expiratory phase (it is usually the initial alteration $)^{25}$. Physical therapy such as percussion or other techniques to mobilize secretions is not enough in patients with $\mathrm{ALS}^{12}$. Cough assistance techniques are indicated when patients' PCF falls below $270 \mathrm{~L} / \mathrm{min}$; these techniques can be classified as follows:

- Manually assisted cough: manual cough should be considered in patients with conserved glottic function, since artificial inspiratory flows and assisted abdominal movements replace the respiratory muscles, but nothing can replace glottic function ${ }^{8,12,13}$; this technique is carried out in a simple way following this steps:

- With a bag-valve-mask ventilation device $\left(\mathrm{Ambu}^{\odot}\right)$ several assisted breaths are made, asking the patient to retain the air in each of them with the objective of expanding the lung close to total lung capacity (the maximum amount of air inside the thorax after a forced inspiration) $)^{12,13,26,27}$.

- Then, the patient will cough but will use an abdominal push to increase the intra-abdominal pressure and exhale forcefully; this push can be exercised by an assistant directly with their hands on the abdomen of the patient ${ }^{12}$.

- It is common for bronchial secretions to remain in the pharynx or mouth from where they will have to be extracted with a vacuum.

- Mechanical techniques: mechanically assisted cough or mechanical insufflation-exsufflation (MIE) is the most effective alternative in these patients to avoid the accumulation of bronchial secretions, it is especially indicated when the PCF is $<160 \mathrm{~L} / \mathrm{min}^{23,25,26}$, is performed with a mechanical device that accumulates several breaths with positive pressure before suddenly changing to a negative pressure:

- An oronasal mask or tracheotomy connector is placed and positive pressure is applied; the applied pressure can vary between +20 and $+40 \mathrm{CmH}_{2} \mathrm{O}$.

- To simulate a normal cough, the pressure is suddenly changed to negative values, the pressure generated in this phase can vary between 20 and $-40 \mathrm{~cm} \mathrm{H}_{2} \mathrm{O}^{28}$.

- Some MIE equipment incorporates oscillatory waves to fluidize secretions ${ }^{29}$.

- It is common for the bronchial secretions to remain in the pharynx or mouth from where they will have to be extracted with a vacuum.

- 6-8 MIE cycles per session should be administered ${ }^{27}$. Assisted coughing techniques should be applied at least 3 times a day or more frequently as needed $\frac{4,26}{3}$.

\section{Isolated symptoms and special situations}

\section{Sialorrhea}

Sialorrhea among patients with ALS is common, can be socially disabling and hinder the use of $\mathrm{NIMV}_{3}$; it can be treated with oral suction or with pharmacological measures through medications with mild antimuscakinic effect such as oral glycopyrrolate (2-8 mg/day), amitriptyline $(75-150 \mathrm{mg} / \mathrm{day})$, and transdermal scopolamine patch (1.5-3 mg/72 h) among others; if an acceptable therapeutic effect is not obtained, injection of botulinum toxin into the salivary glands can be used; however as the toxin can spread to nearby muscles, it can worsen dysphagia and should be reserved only for gastrostōmy patients; another option to consider is the use of local radiotherapy, which has fewer side effects, but does not last as long as botulinum toxin ${ }^{10,13,30}$.

\section{Dyspnea}

Although there are no clinical trials of the manaigement of dyspnea in ALS, the recommendations for the control of it arise from the clinical contexts where dyspnea is a characteristic symptom of the disease in its terminal phases and is an integral part of management in palliative care ${ }^{31}$. For distressing dyspnea, firstatine drugs are systemic opioids, which can be indicated from the onset of the symptom and not only in the final stage of the disease ${ }^{32}$. Treatment begins with an initial dose 
Table 4. Respiratory complications of ALS and their treatment

\begin{tabular}{|c|c|c|c|}
\hline \multicolumn{2}{|c|}{ Alveolar hypoventilation } & \multicolumn{2}{|c|}{ Poor management of bronchial secretions } \\
\hline Pathology & Treatment & Pathology & Treatment \\
\hline Sleep-related hypoventilation syndrome & Nocturnal NIMV & Pneumonia & $\begin{array}{l}\text {-Hospital management } \\
\text {-Antibiotic } \\
\text {-Techniques of assisted cou }\end{array}$ \\
\hline Chronic respiratory failure & $\begin{array}{l}\text {-Home care ( } 24 \text { h of MV) } \\
\text {-Tracheotomy }\end{array}$ & V/Q alterations & Techniques of assisted coug \\
\hline Acute respiratory failure & Emergency management/ICU & Sialorrhea & $\begin{array}{l}\text {-Amitriptyline } \\
\text {-Scopolamine } \\
\text {-Botulinum toxin }\end{array}$ \\
\hline Dyspnea & $\begin{array}{l}\text {-Opioids } \\
\text {-NIMV }\end{array}$ & Fail to NIMV & $\begin{array}{l}\text {-Tracheotomy } \\
\text {-Palliative care }\end{array}$ \\
\hline
\end{tabular}

ALS. amyotrophic lateral sclerosis; ICU: intensive care unit, MV. mechanical ventilation; NIMV. non-invasive mechanical ventilation; V/C. ventilation/perfusion.

equivalent to $2.5 \mathrm{mg}$ of morphine sulfate every $4 \mathrm{~h}$. The dose should be increased by $30 \%$ every $12 \mathrm{~h}$ until dyspnea improves or intolerable side effects develop. When an adequate relief of symptoms is obtained, the use of a long-acting opiate such as oral or transdermal fentan$y$ is recommended. For exacerbations of dyspnea, doses of recap are used, which are $10 \%$ of the total daily dose administered as needed each hour for oral medications or every $30 \mathrm{~min}$ for parenteral medications.

\section{Vaccination}

Vaccination against influenza and pneumococcus is recommended following the corresponding schemes ${ }^{4}$.

\section{Oxygen}

Patients with early respiratory failure should not be treated with oxygen without other forms of ventilatory support (NIMV or IMV), since oxygen therapy in respiratory failure suppresses the hypoxic drive and increases the risk of hypercapnia ${ }^{13}$.

\section{Acute respiratory failure}

Despite the lack of randomized controlled studies, there is agreement on the effectiveness of NIMV to prevent endotracheal intubation in acute respiratory failure events, thus, in one study, three out of four patients who had previously rejected the tracheotomy, but not the NIMV they survived an episode of acute respiratory failure treated with NIMV; the factors associated with success are the correct programming of the ventilation devices, the availability of several types of interfaces (masks) and the proper management of secretions ${ }^{8}$; the main factor limiting the success of NIMV during a respiratory infection is the severity of bulbar dysfunction with a cutoff point on the Norris Scale of 12 points (sensitivity 0.90 , specificity 0.92 , positive predictive value 0.76 , and negative predictive value 0.97$)^{33}$.

The complete pulmonary complications of ALS and their treatments are summarized in table 4.

\section{Follow-up}

The care of patients with ALS should be multidisciplinary and ideally should be performed in specialized centers involving: neurologists, pulmonologists, otölaryngologists, rehabilitation physicians, psychologists, and psychiatrists among others; all with the common goal of increasing survival, improve quality of life, and decreasing hospitalizations from acute events; these specialized centers usually offer appointments withy different specialists in a single visit, reducing the trips of patients to the hospital and, consequently, their fatigue. Quarterly appointments are usually proposed, with Eariations according to the progression of the disease

\section{Conclusions}

The respiratory complications of ALS represent a serious problem for people with this disease and are secondary to the weakness of the muscles that generate respiration; non-IMV and assisted cough (manual or mechanical) are the two most cost/effective techniques to treat alveolar hypoventilation and poor secrétion management, respectively, these tools used in conjunction prolong survival and improve the quality of life of the patients with ALS. 


\section{Conflicts of interest}

All authors of the manuscript declare no conflicts of interest or relationship with the pharmaceutical industry.

\section{Funding}

This manuscript has no external funding source.

\section{Acknowledgments}

We thank the Latin American Association of Thorax (ALAT) and the Spanish Society of Pneumology and Thoracic Surgery (SEPAR) for the grant to Monserrat Evelia Arroyo Rojas.

\section{Ethical disclosures}

Protection of human and animal subjects. The authors declare that the procedures followed were in accordance with the regulations of the relevant clinical research ethics committee and with those of the Code of Ethics of the World Medical Association (Declaration of Helsinki).

Confidentiality of data. The authors declare that they have followed the protocols of their work center on the publication of patient data.

Right to privacy and informed consent. The authors declare that no patient data appear in this article.

\section{References}

1. Braun AT, Caballero-Eraso C, Lechtzin N. Amyotrophic lateral sclerosis and the respiratory system. Clin Chest Med. 2018;39:391-400.

2. Lechtzin N. Respiratory effects of amyotrophic lateral sclerosis: problems and solutions. Respir Care. 2006;51:871-81.

3. Martínez HR, Parada-Garza JD, Meza ME, González-Garza MT, Moreno-Cuevas JE. Esclerosis lateral amiotrófica. Contribución de la neurología Mexicana de 1998 a 2014. Rev Mex Neuroci. 2014;15:355-62.

4. van Es MA, Hardiman O, Chio A, Al-Chalabi A, Pasterkamp RJ, Veldink JH, et al. Amyotrophic lateral sclerosis. Lancet. 2017:390:2084-98.

5. Brown RH, Al-Chalabi A. Amyotrophic lateral sclerosis. N Engl J Med. 2017;377:162-72.

6. Tard C, Defebvre L, Moreau C, Devos D, Danel-Brunaud V. Clinical features of amyotrophic lateral sclerosis and their prognostic value. Rev Neurol (Paris). 2017;173:263-72.

7. Martínez HR, Molina-López JF, Cantú-Martínez L, González-Garza MT, Moreno-Cuevas JE, Couret-Alcaraz $\mathrm{P}$, et al. Survival and clinical features in hispanic amyotrophic lateral sclerosis patients. Amyotroph Lateral Scler. 2011;12:199-205.

8. Ambrosino N, Carpenè N, Gherardi M. Chronic respiratory care for neuromuscular diseases in adults. Eur Respir J. 2009;34:444-51.
9. Chérrez-Ojeda I, Tafur A. Evaluación pulmonar en la esclerosis tateral amiotrófica. Rev Ecuat Neurol. 2003;12:24-7.

10. Quarracino C, Rey RC, Rodríguez GE. Esclerosis lateral amiotrófica (ELA): seguimiento y tratamiento. Neurol Argent. 2014;6:91-5.

11. Pattinson KT, Turner MR. A wider pathological network underlying breathlessness and respiratory failure in amyotrophic lateral sclerosis. Eur Respir J. 2016;47:1632-4.

12. Pfeffer G, Povitz M, Gibson GJ, Chinnery PF. Diagnosis of muscle diseases presenting with early respiratory failure. J Neurol. 2015;262:1101-14.

13. Soriani MH, Desnuelle C. Care management in amyotrophic lateral sclerosis. Rev Neurol (Paris). 2017:173:288-99.

14. Gartman EJ. Pulmonary function testing in neuromuscular and chest wall disorders. Clin Chest Med. 2018;39:325-34.

15. Berry RB, Albertario CL, Harding S, Lloyd RM, Plante DT, Quan SF, et al. The AASM Manual for the Scoring of Sleep and Associated Events:? fules, Terminology and Technical Specifications, Version 2.5. American Academy of Sleep Medicine. Annual Meeting; 2018.

16. Aboussouan LS, Mireles-Cabodevila E. Sleep-disordered breathing in neuromuscular disease: diagnostic and therapeutic challenges. Chest. 2017; 152:880-92.

17. Ahmed RM, Newcombe RE, Piper AJ, Lewis SJ, Yee BJ, Kiernan MC et al. Sleep disorders and respiratory function in amyotrophic lateral sclerosis. Sleep Med Rev. 2016;26:33-42.

18. Howell BN, Newman DS. Dysfunction of central control of breathing in amyotrophic lateral sclerosis. Muscle Nerve. 2017:56:197-201.

19. Petrov D, Mansfield C, Moussy A, Hermine O. ALS clinical trials review: 20 years of failure. Are we any closer to registering a new treatment? Front Aging Neurosci. 2017;9:68.

20. Selim BJ, Wolfe L, Coleman JM $3^{\text {rd }}$, Dewan NA. Initiation of noninvasive ventilation for sleep related hypoventilation disorders: advanced modes and devices. Chest. 2018;153:251-65.

21. Benditt JO. Pathophysiology of neuromuscular respiratory diseases: Clin Chest Med. 2018;39:297-308.

22. Hess DR. Noninvasive ventilation for neuromuscular disease. Clin Chest Med. 2018;39:437-47.

23. Niedermeyer S, Murn M, Choi PJ. Respiratory failure in amyotrophic lateral Sclerosis. Chest. 2019;155:401-8.

24. Hazenberg A, Kerstjens HA, Prins SC, Vermeulen KM, Wijkstra PJ. Initiation of home mechanical ventilation at home: a randomisedcontrolled trial of efficacy, feasibility and costs. Respir Med. +2014 ; 108:1387-95.

25. Finder JD. Airway clearance modalities in neuromuscular disease.Paediatr Respir Rev. 2010;11:31-4.

26. Chiner E, Sancho-Chust JN, Landete P, Senent C, Gómez-Merīno E. Técnicas complementarias a la ventilación mecánica domiciliaria. Arch Bronconeumol. 2014;50:546-53.

27. Sancho J, Servera E, Bañuls P, Marín J. Effectiveness of assisted and unassisted cough capacity in amyotrophic lateral sclerosis patients. Amyotroph Lateral Scler Frontotemporal Degener. 2017;18:498-504.

28. Sancho J, Servera E, Marín J, Vergara P, Belda FJ, Bach JR, et al. Effect of lung mechanics on mechanically assisted flows and volumes.'Am J Phys Med Rehabil. 2004;83:698-703.

29. Sancho J, Bures E, de La Asunción S, Servera E. Effect of high-frequency oscillations on cough peak flows generated by mechanical in-exsufflation in medically stable subjects with amyotrophic lateral sclerosis. Respir Care. 2016:61:1051-8.

30. Britton D, Karam C, Schindler JS. Swallowing and secretion management in neuromuscular disease. Clin Chest Med. 2018;39:449-57.

31. Miller RG, Jackson CE, Kasarskis EJ, England JD, Forshew D, Johnston $W$, et al. Practice parameter update: the care of the patient with amyotrophic lateral sclerosis: multidisciplinary care, symptom management, and cognitive/behavioral impairment (an evidence-based review): report of the quality standards subcommittee of the American academy of neurology. Neurology. 2009;73:1227-33.

32. Lanken PN, Terry PB, Delisser HM, Fahy BF, Hansen-Flaschen J Heffner JE, et al. An official American thoracic society clinical policy statement: palliative care for patients with respiratory diseases and eritical illnesses. Am J Respir Crit Care Med. 2008;177:912-27.

33. Servera E, Sancho J, Bañuls P, Marín J. Bulbar impairment score predicts noninvasive volume-cycled ventilation failure during an acuterespiratory tract infection in ALS. J Neurol Sci. 2015;358:87-91. 